\title{
Response to Intervention and the Pyramid Model
}

\author{
Lise Fox, PhD; Judith Carta, PhD; Phillip S. Strain, PhD; \\ Glen Dunlap, PhD; Mary Louise Hemmeter, PhD
}

\begin{abstract}
Response to Intervention (RtI) is a systematic decision-making process that has gained widespread popularity as a problem-solving framework for organizing hierarchies of evidence-based interventions in the context of ongoing progress monitoring. Initially applied to literacy instruction, RtI is being incorporated into an expanding breadth of domains, including early intervention and the prevention of social-emotional delays and the occurrence of challenging behaviors. In this article, we describe RtI and its relationship to the "Pyramid Model" (L. Fox, G. Dunlap, M. L. Hemmeter, G. Joseph, \& P. Strain, 2003) for promoting social, emotional, and behavioral development of young children. The 2 approaches have close parallels and are considered to be highly compatible. The discussion examines this congruence, identifies challenges in need of resolution, and emphasizes the exciting promise offered by the emergence and implementation of the 2 problemsolving and decision-making frameworks. Key words: challenging behavior, intervention, social development
\end{abstract}

$\mathbf{R}$ ESPONSE TO INTERVENTION (RtI) offers a comprehensive model for the prevention of delays in learning and behavior. Although this problem-solving process was initially designed for application within kindergarten to 12 th-grade programs, there is substantial research that supports the value of the model for application within early childhood programs. This article provides an overview of RtI and discusses the Pyramid Model (Fox, Dunlap, Hemmeter, Joseph, \& Strain, 2003) for promoting young children's social compe-

\footnotetext{
Autbor Affiliations: Department of Child and Family Studies, University of South Florida, Tampa (Drs Fox and Dunlap); Juniper Gardens Children's Project, University of Kansas, Kansas City (Dr Carta); School of Education and Human Development, University of Colorado at Denver, Denver (Dr Strain); and Department of Special Education, Vanderbilt University, Nashville, Tennessee (Dr Hemmeter).
}

The preparation of this manuscript was supported by the Technical Assistance Center on Social Emotional Intervention for Young Children, Office of Special Education Programs, US Department of Education (H326B070002).

Corresponding Autbor: Lise Fox, PbD, Department of Child and Family Studies University of South Florida, 13301 Bruce B Davis Blvd, Tampa, FL 33612 (fox@fmbi.usf.edu). tence and preventing behavior challenges to provide guidance to early childhood professionals and program administrators as they develop policies and procedures related to the adoption of RtI.

\section{RESPONSE TO INTERVENTION}

RtI is a systematic decision-making process designed to allow for early and effective responses to children's learning and behavioral difficulties, provide children with a level of instructional intensity matched to their level of need, and then provide a databased method for evaluating the effectiveness of instructional approaches. RtI relies on evidence-based instructional practices and frequent progress monitoring to provide the data necessary to make decisions about child progress and need for more intensive intervention. The process has its roots in applied behavior analysis, precision teaching, diagnostic prescriptive teaching, curriculumbased measurement, prereferral intervention, data-measured decision, and team-based problem solving (Sugai, 2007). It is intended to reduce unnecessary referrals to special education by ensuring that all children in the general education setting have access to 
high-quality curriculum and instruction that are provided in a cascade of intensity. Although the process is not intended to replace special education and its procedural safeguards, it was introduced as special education policy in the Individuals with Disabilities Education Improvement Act of 2004 (IDEA, 2004).

\section{Critical features of RtI}

RtI is based on the premise that supports are provided early, monitored systematically, and adjusted intentionally to respond to individual children's needs, thus preventing the more traditional practice of waiting for a child to demonstrate failure and then beginning a process of evaluation and referral to special education. Instead, RtI includes several features that allow programs to more quickly and efficiently provide the type of support children need to demonstrate successful outcomes. These features include the following:

1. Universal screening: The performance of all students is evaluated systematically to identify those who are (a) making adequate progress, $(b)$ at some risk of failure if not provided extra assistance, or (c) at bigh risk of failure if not provided specialized supports.

2. Continuous progress monitoring: Student progress is assessed on a regular and frequent basis in order to identify when inadequate growth trends might indicate a need for increasing the level of instructional support to the student.

3. Continuum of evidence-based interventions: There are multiple levels, or a "cascade," of interventions derived from scientifically validated research that vary in intensity or level of support. Typically, a core curriculum is provided for all students, modification of this core is arranged for a targeted group of students who do not show adequate growth in response to the core curriculum, and an individualized intensive curriculum is implemented for students who do not show adequate growth in response to the modified curriculum.
4. Data-based decision making and problem solving: Instructional decision making is based on student performance or growth on curricular outcomes and modifications or adaptations that are implemented when insufficient growth is noted.

5. Implementation fidelity: Specific procedures are used to regularly document the level of implementation that occurs (e.g., were the modifications of the teaching practices implemented consistently and with a high degree of accuracy) across features of the model.

\section{Research support for RtI}

Although numerous studies have been carried out to validate the specific features of RtI, the evidence base establishing the effectiveness of various models or approaches to RtI is still emerging (Hughes \& Dexter, 2008; Torgesen, 2009; VanDerHeyden, Witt, \& Gilbertson, 2007). Available evidence indicates that use of RtI models can improve the academic performance of at-risk students, most notably in the area of early reading skills (e.g., O'Connor, Harty, \& Fulmer, 2005; Vaughn, Linan-Thompson, \& Hickman, 2003). Other studies have shown that students who were involved in programs employing RtI models had reduced rates of special education referral and/or placement (e.g., Bollman, Silberglitt, \& Gibbons, 2007; Marston, Muyskens, Lau, \& Canter, 2003; O'Connor et al., 2005), or performed better on academic behaviors such as time-on task and task completion (Buysse \& PeisnerFeinberg, 2009; Kovaleski, Gickling, Morrow, \& Swank, 1999).

\section{Expansion of RtI to social behavior}

Although most studies of RtI have focused on instructional practices in academic areas, some applications of RtI have been reported in the area of instructional support for social behavior, such as School-wide Positive Behavior Support (Sugai et al, 2000). RtI models focusing on academic instruction or support for social behavior share an emphasis on 
prevention, and both types of models have created tiered approaches that have their roots in public health (e.g., Simeonnson, 1994). As Sugai (2001) has described, 3-tier models that are implemented in academic systems or behavioral systems are based on the following components:

1. Primary tier prevention with all students being exposed to a core curriculum to prevent later problems. Regular screening identifies students who are unsuccessful in response to instruction with only the core curriculum.

2. Secondary tier prevention that is targeted at at-risk students who need some additional instructional support beyond the core curriculum.

3. Tertiary tier prevention that is generally more intensive and individualized and is carried out to remediate academic performance or reduce complications or severity of problem behavior.

A critical component underlying the 3 tiers of instructional support are clear decision rules based on student performance that determine when a student moves up or down the continuum of tiers. Therefore, in either academic or social systems using an RtI approach, the focus is on timely screening, ongoing progress monitoring, and data-based decisions so that more effective interventions can be provided for students whose academic or social behaviors are not responsive to the core curriculum and more intensive interventions (Sugai, 2007). Preventing academic failure and challenging behaviors is the underlying premise of RtI so that all students' learning is maximized.

\section{APPLYING RTI IN EARLY EDUCATION}

RtI has pragmatic appeal for early education as it is consistent with the conceptual and theoretical framework of early childhood special education and national recognition of the critical importance of high-quality early childhood programs to promote young children's development (Coleman, Buysse, \& Neitzel, 2006; VanDerHeyden \& Snyder, 2006). Early childhood special education was developed as a prevention model with an emphasis on the importance of providing intervention and supports to very young children and their families to minimize the impact of disability, risk, or developmental delay on the child's developmental trajectory and learning outcomes (Simeonnson, 1991). Similarly, Head Start, Early Head Start, Title I Preschool, and state-funded preschool programs have been developed in response to the overwhelming research on the benefit that can be realized when young children attend high-quality early education programs or receive intervention services to address child and family needs (Guralnick, 1997, 2005; Ramey \& Ramey, 1998). The common focus across current early childhood initiatives is the provision of early education, intervention, and family support that will prevent future academic challenges and developmental delays or disabilities (VanDerHeyden \& Snyder, 2006).

In early childhood programs, RtI offers a process for ensuring the delivery of highquality education and care at the universal level to support the development of all children and a dynamic decision-making process for determining how to identify and assist young children in need of additional intervention to ensure their developmental progress (Coleman et al., 2006; Greenwood et al., 2008). A tiered intervention model is an excellent fit with the presumption in early childhood and early intervention that young children should be educated within natural environments and inclusive settings and that intervention should be designed to match child and family needs. The key component to using such a model is the identification of research-based curriculum that can be arranged into a tiered model of intervention, and matched to a child's learning and behavioral needs.

The need for an intervention framework for addressing young children's social and behavioral concerns is supported by a substantial body of research that illustrates the detrimental effects of social-emotional delay and challenging behavior on children's school 


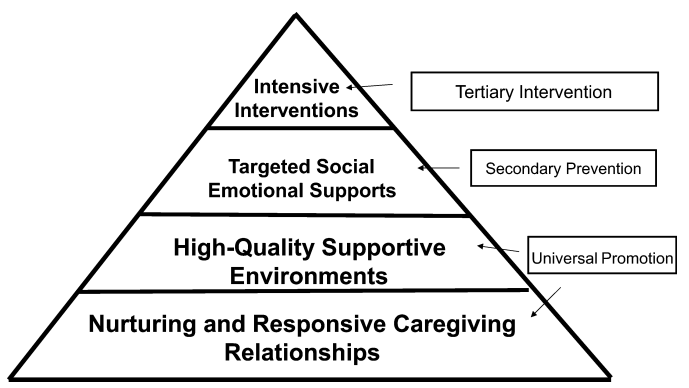

Figure 1. Pyramid Model.

achievement and developmental outcomes. In early childhood, the Pyramid Model (Fox et al., 2003) has been identified as a tiered in tervention model that provides guidance for the design and delivery of evidence-based interventions to promote the social development of young children and provide more intensive intervention for children who have social-emotional delays or behavioral challenges. In the following section, we describe the Pyramid Model intervention practices and follow with a description of how this tiered intervention model can be used as an RtI process.

\section{The Pyramid Model intervention practices}

The Pyramid Model (Fig 1) provides a tiered intervention framework of evidence-based interventions for promoting the social, emotional, and behavioral development of young children (Fox et al., 2003; Hemmeter, Ostrosky, \& Fox, 2006). The model describes 3 tiers of intervention practice: universal promotion for all children; secondary preventions to address the intervention needs for children at risk of social-emotional delays; and tertiary interventions needed for children with persistent challenges. The Pyramid Model was initially described as an intervention framework for 2- to 5-yearold children within early childhood settings. However, newer iterations of the model provide guidance for the implementation of the framework with infants, toddlers, and preschoolers and include interventions needed to support children who are typically developing and who have or are at risk for developmental delays or disabilities (Hunter \& Hemmeter, 2009).

Tier 1: Universal promotion. The first tier of the Pyramid Model involves 2 levels of practices that are critical to promoting the social development of young children. The first level of practices is the provision of nurturing and responsive caregiving relationships to the child. This includes the family or primary caregiver and the caregiver or teacher within an early childhood program. In addition to a focus on the relationship to the child, this level of the pyramid also describes the need for developing partnerships with families and collaborative relationships among intervention or classroom team members.

There is ample evidence that the provision of a responsive and nurturing relationship is pivotal to a child's development (National Research Council, 2001; Shonkoff \& Phillips, 2000). In their early years, children exist within a web of relationships with parents, teachers, other caring adults in their lives, and eventually, peers. This web supplies the context within which healthy socialemotional growth and the capacity to form strong positive relationships with adults and peers develop. The relationships level of the pyramid model includes practices such as actively supporting children's engagement; embedding instruction within children's routine, planned, and play activities; responding to children's conversations; promoting the communicative attempts of children with language delays and disabilities; and providing encouragement to promote skill learning and development.

The second level of universal promotion is the provision of supportive environments. Within home and community settings, this level of the pyramid refers to the provision of predictable and supportive environments and family interactions that will promote the child's social and emotional development. Universal practices for children with or at risk for delays or disabilities include receiving instruction and support within inclusive environments that offer the rich social context 
that is essential to the development of social skills and peer relationships.

In early care and education programs, this level of the pyramid refers to the design of classrooms and programs that meet the standards of high-quality early education. This includes the implementation of a curriculum that fosters all areas of child development, the use of developmentally and culturally appropriate and effective teaching approaches, the design of safe physical environments that promote active learning and appropriate behavior, the provision of positive and explicit guidance to children on rules and expectations, and the design of schedules and activities that maximize child engagement and learning. At this level of the pyramid, families who receive home visiting or early intervention services might be provided with information and support on establishing predictable routines; implementing specialized healthcare and treatment procedures; teaching social, emotional, and other skills within play and routine activities; promoting language and communication development; and fostering the development of play and social interaction skills.

Tier 2: Secondary prevention. The secondary or prevention level of the Pyramid includes the provision of explicit instruction in social skills and emotional regulation. In early childhood programs, all young children will require adult guidance and instruction to learn how to express their emotions appropriately, play cooperatively with peers, and use social problem-solving strategies. However, for some children it will be necessary to provide more systematic and focused instruction to teach them social-emotional skills. Children might need more focused instruction on skills such as identifying and expressing emotions; self-regulation; social problem solving; initiating and maintaining interactions; cooperative responding; strategies for handling disappointment and anger; and making friends (Denham et al., 2003; Joseph \& Strain, 2003; Strain \& Joseph, 2006). Families in early intervention programs might need guidance and coaching from their early intervention provider on how to promote their child's de- velopment of targeted social and emotional skills. Families of infants and young toddlers might need guidance and support for helping the very young child regulate emotions or stress and understand the emotions of others.

Tier 3: Tertiary interventions. When children have persistent challenging behavior that is not responsive to interventions at the previous levels, comprehensive interventions are developed to resolve problem behavior and support the development of new skills. At this level of the Pyramid Model, positive behavior support (PBS) is used to develop and implement a plan of intensive, individualized intervention. PBS provides an approach to addressing problem behavior that is individually designed, can be applied within all natural environments by the child's everyday caregivers, and is focused on supporting the child in developing new skills (Dunlap \& Fox, 2009; Lucyshyn, Dunlap, \& Albin, 2002).

The process begins with convening the team that will develop and implement the child's support plan. At the center of the team is the family and child's teacher or other primary caregivers. The PBS process begins with functional assessment to gain a better understanding of the factors that are related to the child's challenging behavior. Functional assessment ends with the development of hypotheses about the functions of the child's challenging behavior by the team. These hypotheses are used to develop a behavior support plan. The behavior support plan includes prevention strategies to address the triggers of challenging behavior; replacement skills that are alternatives to the challenging behavior; and strategies that ensure challenging behavior is not reinforced or maintained. The behavior support plan is designed to address home, community, and classroom routines where challenging behavior is occurring. In this process, the team also considers supports to the family and strategies to address broader ecological factors that affect the family and their support of the child.

The Pyramid Model has been widely disseminated by 2 federally funded research and training centers (i.e., Center on the 
Social Emotional Foundations for Early Learning [www.vanderbilt.edu/csefel] and the Technical Assistance Center on Social Emotional Interventions for Young Children [www.challengingbehavior.org]). In the last several years, faculty members from these centers have been involved in assisting states and programs with program-wide adoption of the Pyramid Model (Fox \& Hemmeter, 2009; Hemmeter, Fox, Jack, Broyles, \& Doubet, 2007). In addition, tools have been developed to support the implementation of the Pyramid Model, including an implementation fidelity tool to assess a teacher's implementation of these practices, implementation materials to support teachers in using the practices, and the identification of the professional development approaches needed to support teachers in achieving fidelity (Hemmeter, Fox, \& Snyder, 2008).

Program-wide adoption of the Pyramid Model brings the Pyramid Model into a systematic, problem-solving process that allows for the identification of children who are in need of more focused or intensive intervention and the use of data to monitor child progress and outcomes. Thus, program-wide adoption of the Pyramid Model offers a viable demonstration of the implementation of an RtI process for young children's social and behavioral development. In the following section, we discuss how the Pyramid Model, through program-wide adoption, is used as an RtI to promote the social and behavioral development of young children.

\section{The Pyramid Model as an RtI}

The Pyramid Model offers the continuum of evidence-based practices to promote social development and address challenging behavior that is a critical element of RtI. Programwide adoption of the Pyramid Model brings the processes and procedures needed for the RtI problem-solving process. Before describing how the Pyramid Model can be used as an RtI, it is important to iterate some key assumptions that are central to Pyramid Model implementation as these assumptions influence how the Pyramid Model is used as an RtI.
These assumptions are as follows:

1. Tier 3 interventions are not synonymous with special education services: The Pyramid Model was designed for implementation by early educators within all child care, preschool, home visiting, early intervention, Head Start, and early childhood special education programs. The framework was not designed as a path to special education services and a child receiving services through special education might be served at any of the intervention tiers. For example, a child enrolled in early intervention services might not need anything beyond tier 1 interventions to ensure healthy social-emotional development while another child in early intervention might have social/behavioral concerns.

2. Inclusive social settings are the context for intervention: The focus of the Pyramid Model is to foster social-emotional development. This requires a rich social milieu as the context of intervention and instruction. Thus, the model is designed for implementation within natural environments, interactions with the child's natural caregivers and peers, and classroom settings that offer opportunities for interactions with socially competent peers. Interventions do not involve pull out from those settings; rather, they are dependent on a rich social context where the number of opportunities to learn and practice social skills can be optimized.

3. Pyramid model tiers have additive intervention value: Each tier of intervention builds upon the previous tier. Tier 2 and 3 interventions are reliant on the provision of practices in the lower tiers to promote optimal child outcomes.

4. Instructional precision and dosage increases as you move up the Pyramid tiers: The intervention practices and foci in tier 2 and 3 are not uniquely different teaching targets or approaches than the universal practices used to foster all children's social development. The 
differences between tiers are evident in the specificity of the instructional target, the precision of the instructional approach, the frequency of monitoring children's responsiveness to intervention efforts, and the number of instructional opportunities delivered to children at each level.

5. Efficiency and effectiveness of intervention is of primary importance: When children have challenging behavior or social-emotional risks, it is imperative that intervention is delivered quickly and effectively. There is ample research evidence that when children's challenging behavior persists, the problems are likely to worsen and become compounded by related problems including peer and adult rejection and coercive relationships (Dodge, Coie, \& Lynam, 2006; Moreland \& Dumas, 2008). Thus, the Pyramid Model has been provided to early educators so that practitioners and programs can provide the most effective intervention needed to immediately support the child and result in desired child outcomes. Children in need of tier 2 or tier 3 approaches should have immediate access to those interventions.

6. Families are essential partners: The interventions involved in the Pyramid Model are reliant on the participation of families. All families are provided with information on how to promote their child's social development. When children are in need of tier 2 or 3 interventions, families are involved in the provision of systematic intervention by providing increased opportunities for the child to learn and practice new skills in the context of everyday activities and routines in the home and community. When children have persistent challenges, families and other persons involved with the child form a collaborative team to develop and implement comprehensive interventions and supports that are applied in all of the child's routines and activities.
A central element of the RtI process is the use of universal screening and progress monitoring data to identify children who are at risk of developmental delays and to ensure that children are progressing in response to instruction. In the adoption of the Pyramid Model, universal screening is used to identify children who might have socialemotional delays and are in need of more systematic supports or instruction. Screening tools, such as the Ages and Stages Questionnaires: Social-Emotional (Squires, Bricker, \& Twombly, 2002) or a similar instrument, offer an efficient mechanism to identify children who might need further assessment, closer monitoring, or more intensive intervention. In addition to using a universal, standardized screening measure to identify children who might need additional support, programs systematically monitor challenging behavior incidences to determine if an individual child or teacher might need more support or need additional intervention.

The results of universal screening (e.g., Squires et al., 2002) paired with additional data on incidents of challenging behavior will provide the program with information to identify children who might be in need of tier 2 or tier 3 levels of intervention. Children who have social-emotional delays, who struggle with meeting developmentally appropriate social and behavioral expectations, or who have chronic but mild forms of problem behavior should be provided with systematic instruction focused on the development of targeted social-emotional skills. Children whose persistent challenging behaviors interfere with their participation in daily activities or cause harm to themselves or others are children who are targeted immediately for tier 3 interventions.

Tier 2 interventions involve the development of an intervention plan and progress monitoring system for children who need targeted social-emotional intervention to prevent the development of challenging behavior or remediate social-emotional delays. The intervention plan includes identifying the specific social-emotional skill or skills that are 
targeted for intervention; specifying the individualized instructional approach or prompting system that will be used; ensuring that sufficient instructional and practice opportunities will be delivered to the child; and developing an efficient method for collecting meaningful data on the child's responsiveness to intervention.

Tier 3 intervention involves the implementation of an assessment-based behavior support plan to address the environmental triggers of challenging behavior, provide instruction of communication and social skills that serve as replacement to challenging behavior, and to ensure that new skills are being reinforced and problem behavior is not being maintained by events or interactions with others. The behavior support plan is facilitated by a behavior specialist or mental health consultant (or another professional with expertise in behavioral interventions) who convenes a team (including the family and teacher) that works together to conduct a functional assessment and design the behavior support plan. In addition, an easy-to-use progress monitoring chart is developed to track the responsiveness of the child to the behavior support plan. This typically takes the form of a data collection system that is used every few days and provides information on the child's use of the targeted replacement skill or prompting level needed to support the use of the skill and data on the severity or frequency of the child's engagement in the challenging behavior targeted for reduction. Tier 3 intervention also includes the development of a procedural fidelity checklist that is used to ensure that all components of the behavior support plan are being implemented as intended.

A critical element for RtI is implementation fidelity. The Teaching Pyramid Observation Tool (TPOT) has been developed to assess the teacher's capacity to deliver the tiered model of intervention practices (Hemmeter et al., 2008). It is used as a professional development tool to identify the teaching practices that are in place and areas of focus for training, coaching, and implementation. An important feature of the TPOT is that it can be used as an implementation fidelity measure to assess if the universal tier of practices is in place and delivered to the classroom as a group. However, when an intervention is delivered to an individual child, there must be a measure to determine if interventions at Tiers 2 and 3 are delivered with intended precision and intensity. This type of implementation fidelity requires that a simple data collection mechanism be developed to track the delivery of instruction or intervention at tiers 2 and 3 as well as the child's progress in responding to the intervention.

The adoption of the Pyramid Model as an RtI within an early childhood program requires an infrastructure of systems and supports to ensure that practitioners can implement the model with fidelity and that the model becomes fully integrated into the program (Fox \& Hemmeter, 2009; Hemmeter et al., 2006). Infrastructure features that support the implementation of an RtI include (1) the development of clear procedures for screening, progress monitoring, and the delivery of more intensive tiers of intervention to children; (2) the development of strategies and systems for family involvement within each tier; (3) professional development and ongoing support to teachers for implementation fidelity; (4) access to expertise in the design and implementation of tier 2 and tier 3 interventions; and (5) procedures for efficient and meaningful data collection and data-based decision making.

\section{TOWARD A COMPREHENSIVE AND OPTIMAL IMPLEMENTATION OF RTI}

Although RtI is clearly a promising model for prevention and data-based problem solving, and although the Pyramid Model addresses the promotion of healthy socialemotional development and the prevention of challenging behavior in a manner that is highly compatible with RtI, there are issues in need of further development and research in order for the approaches to be implemented easily and effectively in the full array of early 
childhood programs. The following section addresses these issues.

A first concern involves the status of evidence-based practices that can be implemented with confidence to prevent or remediate challenging behaviors. The effectiveness of the Pyramid Model and RtI for social-emotional behaviors is dependent upon the demonstrated efficacy and efficiency of the strategies used at each tier of the hierarchy. At this point, there is considerable research available documenting the effects of intervention practices at tier 2 and tier 3 of the model (e.g., Dunlap \& Fox, 2009; Hemmeter et al., 2006; Strain \& Schwartz, 2009). However, there is much less research information with which to establish the preventive effects of tier 1 (primary prevention) strategies. The variables identified as essential tier 1 strategies, related to relationships and environmental arrangements, are derived from consensus documents and compelling indirect research findings (Birch \& Ladd, 1998; Bodrova \& Leong, 1998; Cox, 2005; Howes \& Hamilton, 1992; Howes, Phillips, \& Whitebrook, 1992; Howes \& Smith, 1995; Kontos, 1999; National Research Council, 2001; Peisner-Feinberg et al., 2000; Phillips, McCartney, \& Scarr, 1987; Pianta, Steinberg, \& Rollins, 1995), but there is very little rigorous research that has directly tested the effects of these variables in promoting healthy social-emotional development and preventing the occurrence of challenging behaviors. Such research will be extremely valuable in determining the parameters of tier 1 strategies that are most efficient and effective.

Research is also needed to evaluate factors involved in facilitating implementation of the model in early childhood service programs (cf., Fixsen, Naoom, Blase, Friedman, \& Wallace, 2005). In particular, development of the model will benefit greatly from evaluation, correlational, and case study investigations focused on systems variables (eg, administrative practices, policies, personnel preparation, and funding formulae) that contribute to fidelity and sustainability of the data collection, problem-solving, and procedural aspects of the approach. At this point, there are some very useful and encouraging examples of large-scale (program-wide) implementation (Fox, Jack, \& Broyles, 2005; Hemmeter \& Fox, 2009; Hemmeter, et al., 2007), but the need remains for more focused examinations to help refine the model's components and scale-up capabilities.

Finally, it is important to look at approaches to social-emotional development in the overall context of strategies for enhancing intellectual and academic development and readiness for school (kindergarten) for all children. In some respects, the application of RtI models to academic (eg, literacy and numeracy) concerns has been studied more extensively than RtI applications to social, emotional, and behavioral development. Ultimately, however, the approaches need to be integrated and considered as a comprehensive, interconnecting model addressing all aspects of optimal development of young children. Attainment of this goal will require a clear focus on the design of inclusive programs with a full appreciation for the needs of a diverse population of children, including children with multiple risk factors and a range of disabilities.

\section{Summary}

RtI provides a useful, problem-solving process that is highly compatible with the goals and priorities of early childhood education and early intervention. The Pyramid Model (Fox et al., 2003) is a multitiered model of prevention and intervention for healthy socialemotional development and the prevention of challenging behaviors. In this article, we have attempted to describe the close relationship between RtI and the Pyramid Model and to illustrate how the Pyramid Model can be viewed as a constructive application of RtI in the context of social, emotional, and behavioral functioning. A major point of this discussion has been to emphasize the exciting promise of these approaches as we seek to improve the capacity of early childhood programs for preventing the serious consequences associated with challenging behavior and promoting healthy development for all young children. 


\section{REFERENCES}

Birch, S. H., \& Ladd, G. W. (1998). Children's interpersonal behaviors and the teacher-child relationship. Developmental Psychology, 34(5), 934-946.

Bodrova, E., \& Leong, D. J. (1998). Development of dramatic play in young children and its effects on self-regulation: The Vygotskian approach. Journal of Early Childbood Teacher Education, 19, 115124.

Bollman, K. A., Silberglitt, B., \& Gibbons, K. A. (2007). The St. Croix River education district model: Incorporating systems-level organization and a multi-tiered problem-solving process for intervention delivery. In S. R. Jimerson, M. K. Burns, \& A. M. VanDerHeyden (Eds.), Handbook of response to intervention: The science and practice of assessment and intervention (pp. 319-330). New York: Springer.

Buysse, V., \& Peisner-Feinberg, E. (2009). Recognition and response: Findings from the first implementation study [on-line]. Retrieved October 25, 2009, from http://randr.fpg.unc.edu/sites/randr.fpg.unc. edu/files/KeyFindingsHandout.pdf

Coleman, M. R., Buysse, V., \& Neitzel, J. (2006). Recognition and response: An early intervening system for young children at-risk for learning disabilities. Full report. Chapel Hill: The University of North Carolina at Chapel Hill, FPG Child Development Institute.

Cox, D. D. (2005). Evidence-based interventions using home-school collaboration. School Psychology Quar terly, 20(4), 473-497.

Denham, S. A., Blair, K. A., DeMulder, E., Levitas, J., Sawyer, K., Auerbach-Major, S., et al. (2003). Preschool emotional competence: Pathway to social competence? Child Development, 74, 238256.

Dodge, K. A., Coie, J. D., \& Lynam, D. (2006). Aggression and antisocial behavior in youth. In W. Damon, R. M. Lerner, \& N. Eisenberg (Eds.), Handbook of child psychology: Vol. 3. Social, emotional, and personality development (6th ed., pp. 719-788). New York: Wiley.

Dunlap, G., \& Fox, L. (2009). Positive behavior support and early intervention. In W. Sailor, G. Dunlap, G. Sugai, \& R. Horner (Eds.), Handbook of positive behavior support (pp. 49-72). New York: Springer.

Fixsen, D. L., Naoom, S. F., Blase, K. A., Friedman, R. M., \& Wallace, F. (2005). Implementation research: A synthesis of the literature. Tampa: Florida Mental Health Institute, University of South Florida.

Fox, L., Dunlap, G., Hemmeter, M. L., Joseph, G., \& Strain, P. (2003). The Teaching Pyramid: A model for supporting social competence and preventing challenging behavior in young children. Young Children, 58(4), 48-53.

Fox, L., \& Hemmeter, M. L. (2009). A program-wide model for supporting social emotional development and addressing challenging behavior in early child- hood settings. In W. Sailor, G. Dunlap, G. Sugai, \& R. Horner (Eds.), Handbook of positive behavior support (pp.177-202). New York: Springer.

Fox, L., Jack, S., \& Broyles, L. (2005). Program-wide positive behavior support: Supporting young children's social-emotional development and addressing challenging behavior. Tampa: University of South Florida, Louis de la Parte Florida Mental Health Institute.

Greenwood, C. R., Carta, J. J., Baggett, K., Buzhardt, J., Walker, D., \& Terry, B. (2008). Best practices in integrating progress monitoring and response-tointervention concepts into early childhood systems. In A. Thomas, J. Grimes, \& J. Gruba (Eds.), Best practices in school psychology $\mathrm{V}$ (pp. 535-548). Washington, DC: National Association of School Psychology.

Guralnick, M. J. (1997). The effectiveness of early intervention. Baltimore: Paul $\mathrm{H}$. Brookes.

Guralnick, M. J. (2005). An overview of the developmental systems approach to early intervention. In M. J. Guralnick (Ed.), The developmental systems approach to early intervention (pp. 1-23). Baltimore: Paul H. Brookes.

Hemmeter, M. L., \& Fox, L. (2009). The teaching pyramid: A model for the implementation of classroom practices within a program-wide approach to behavior support. NHSA Dialogue, 12(2), 133-147.

Hemmeter, M. L., Fox, L., Jack, S., Broyles, L., \& Doubet, S. (2007). A program-wide model of positive behavior support in early childhood settings. Journal of Early Intervention, 29, 337-355.

Hemmeter, M. L., Fox, L., \& Snyder, P. (2008). The Teaching Pyramid Observation Tool research edition. Unpublished assessment.

Hemmeter, M. L., Ostrosky, M., \& Fox, L. (2006). Social and emotional foundations for early learning: A conceptual model for intervention. School Psychology Review, 35, 583-601.

Howes, C., \& Hamilton, C. E. (1992). Children's relationships with child care teachers: Stability and concordance with parental attachments. Child Development, 63, 867-878.

Howes, C., Phillips, D., \& Whitebrook, M. (1992). Thresholds of quality: Implications for the social development of children in center-based child care. Child Development 63, 449-460.

Howes, C., \& Smith, E. (1995). Relations among child care quality, teacher behavior, children's play activities, emotional security, and cognitive activity in child care. Early Childbood Research Quarterly, 10, 381404.

Hughes, C., \& Dexter, D. D. (2008). Field studies of RtI programs. Retrieved January 1, 2009, from the RtI Action Network website: http://www.rtinetwork. org/Learn/Research/ar/FieldStudies 
Hunter, A., \& Hemmeter, M. L. (2009). Addressing challenging behavior in infants and toddlers. Zero to Three, 29(3), 5-12.

Individuals with Disabilities Education Improvement Act of 2004, Pub. L. No. 108-446, § 1400 et seq.

Joseph, G. E., \& Strain, P. S. (2003). Comprehensive evidence-based social emotional curricula for young children: An analysis of efficacious adoption potential. Topics in Early Childbood Special Education, 23(2), 65-76

Kontos, S. (1999). Preschool teachers' talk, roles, and activity settings during free play. Early Childbood Research Quarterly, 14(3), 363-383.

Kovaleski, J. F., Gickling, E. E., Morrow, H., \& Swank, H. (1999). High versus low implementation of instructional support teams: A case for maintaining program fidelity. Remedial and Special Education, 20, 170183.

Lucyshyn, J. M., Dunlap, G., \& Albin, R. W. (2002). Families and positive behavior support: Addressing problem behavior in family contexts. Baltimore: Paul H. Brookes.

Marston, D., Muyskens P., Lau, M., \& Canter, A. (2003). Problem-solving model for decision making with high-incidence disabilities: The Minneapolis experience. Learning Disabilities Research and Practice, 18, 187-200.

Moreland, A. D., \& Dumas, J. E. (2008). Categorical and dimensional approaches to the measurement of disruptive behavior in the preschool years: A meta-analysis. Clinical Psychology Review, 28, 1059-1070.

National Research Council. (2001). Eager to learn: Educating Our Preschoolers. Committee on Early Childhood Pedagogy. B. T. Bowman, M. S. Donovan, \& M. S. Burns (Eds). Commission on Behavioral and Social Sciences and Education. Washington, DC: National Academy Press.

O'Connor, R. E., Harty, K. R., \& Fulmer, D. (2005). Tiers of intervention in kindergarten through third grade. Journal of Learning Disabilities, 38, 532-538.

Peisner-Feinberg, E. S., Burchinal, M. R., Clifford, R. M., Culkin, M. L., Howes, C., Kagan, S. L., et al. (2000). The children of the cost, quality, and outcomes study go to school: Technical report. Chapel Hill: University of North Carolina at Chapel Hill, Frank Porter Graham Child Development Center.

Phillips, D. A., McCartney, K., \& Scarr, S. (1987). Childcare quality and children's social development. Developmental Psychology, 23, 537-544.

Pianta, R. C., Steinberg, M., \& Rollins, K. (1995). The first two years of school: Teacher child relationships and deflections in children's classroom adjustment. Developmental and Psychopatbology, 7, 295312.

Ramey, C. T., \& Ramey, S. L. (1998). Early intervention and early experience. American Psychologist, 53, 109120.
Shonkoff, J. P., \& Phillips, D. A. (Eds.) (2000). From neurons to neighborboods: The science of early childhood development. Washington, DC: National Academy Press.

Simeonnson, R. J. (1991). Primary, secondary, and tertiary prevention in early intervention. Journal of Early Intervention, 15, 124-134.

Simeonnson, R. J. (1994). Promoting children's health, education, and well being. In R. J. Simeonsson (Ed.), Risk, resilience, and prevention: Promoting the well-being of all children (pp. 3-12). Baltimore: Paul H. Brookes.

Squires, J., Bricker, D., \& Twombly, E. (2002). Ages and Stages Questionnaires: Social-emotional user's guide. Baltimore: Paul Brookes

Strain, P. S., \& Joseph, G. E. (2006). You've got to have friends: Promoting friendships for preschool children. Young Exceptional Children Monograph Series, 8, 57-66.

Strain, P., \& Schwartz, I. (2009). Positive behavior support and early intervention for young children with autism: Case studies on the efficacy of proactive treatment of problem behavior. In W. Sailor, G. Dunlap, G. Sugai, \& R. H. Horner (Eds), Handbook of positive behavior support (pp. 107-123). New York: Springer.

Sugai, G. (2001, June 23,). School climate and discipline: School-wide positive behavior support. Keynote presentation to and paper for the National Summit on Shared Implementation of IDEA, Washington, DC.

Sugai, G. (2007, December). Responsiveness-tointervention: Lessons learned and to be learned. Keynote presentation at and paper for the RTI Summit, U.S. Department of Education, Washington, DC.

Sugai, G., Horner, R. H., Dunlap, G., Hieneman, M., Lewis, T. J., Nelson, C. M., et al. (2000). Applying positive behavior support and functional assessment in schools. Journal of Positive Behavior Interventions, 2, 131143.

Torgesen, J. K. (2009). The response to intervention instructional model: Some outcomes from a large-scale implementation in Reading First schools. Child Development Perspectives, 3, 38-40.

VanDerHeyden, A. M., \& Snyder, P. (2006). Integrating frameworks from early childhood intervention and school psychology to accelerate growth for all young children. School Psychology Review, 35, 519-534.

VanDerHeyden, A. M., Witt, J. C., \& Gilbertson, D. (2007). A multi-year evaluation of the effects of a response to intervention (RtI) model on identification of children for special education. Journal of School Psychology, 45, 225-256.

Vaughn, S., Linan-Thompson, S., \& Hickman, P. (2003). Response to intervention as a means of identifying students with reading/learning disabilities. $E x$ ceptional Children, 69, 391-409. 